\title{
High performance Ni-YSZ thin-walled microtubes for anode-supported solid oxide fuel cells obtained by powder extrusion moulding
}

\author{
B. Arias-Serrano a, M.E. Sotomayor a, A. Várez a†, B. Levenfeld a, H. Monzón b, M. A. \\ Laguna-Bercero $b$ and A. Larrea $b$ \\ a Departamento de Ciencia e Ingeniería de Materiales, Universidad Carlos III de Madrid, Avda. \\ Universidad 30, 28911 Leganés, Spain. \\ ${ }^{b}$ Instituto de Ciencia de Materiales de Aragón (ICMA), CSIC- Universidad de Zaragoza, C/ María \\ de Luna 3, E-50018 Zaragoza, Spain.
}

+ Corresponding author: Tel: +34 9162494 84; fax: +34 9162494 30. E-mail address: alvar@ing.uc3m.es.

Aiming at the fabrication of microtubular anode-supports for Solid Oxide Fuel Cells (SOFCs) applications, this contribution deals with the production of Ni-YSZ thin-walled tubes $(<1 \mathrm{~mm}$ thickness) via Powder Extrusion Moulding (PEM). The overall method has been optimized with an emphasis on the effect of $\mathrm{NiO}$ particle size using two commercial NiO powders with mean sizes of 0.7 and $8 \mu \mathrm{m}$. A thermoplastic binder system based on polypropylene (PP), paraffin wax (PW) and stearic acid (SA) in a volume ratio of 50, 46 and 4, respectively, was used along with corn starch as a pore forming agent. Different feedstocks with solid loadings varying from 45 to 65 vol.\% were processed and characterized to determine the optimal formulation. Typically, the mixtures exhibited a pseudoplastic behaviour from 100 to 1000 s-1. Feedstocks with finer $\mathrm{NiO}$ particles had the most balanced properties for PEM purpose and an optimal powder volume content of 65 vol.\% was established. After extrusion and debinding steps, defect-free and constant cross-section tubes with $15 \mathrm{~mm}$ of length and $4 \mathrm{~mm}$ of nominal diameter were obtained. Final microstructure and DC conductivity were found to be closely linked to the $\mathrm{NiO}$ particle size, yielding a higher amount of open porosity and a better performance when using finer $\mathrm{NiO}$ powder. Based on this study, packing mechanism was found to be likely limited by the contribution of steric hindrances when dissimilar and coarse powder are mixed, which may play a decisive role in order to set tailored formulations.

\section{Introduction}

Solid Oxide Fuel Cells (SOFCs) have emerged as an alternative to conventional power generators because of their high conversion efficiency and environmentally friendly performance while operating between 700 and $1000{ }^{\circ} \mathrm{C}$. The most common configuration consists of a Ni-YSZ anode, a YSZ electrolyte and a lanthanum strontium-doped manganite (LSM) cathode.1,2 Among the different geometric designs of SOFCs, there is an increasing tendency to develop tubular devices because of their better thermo-mechanical properties, sealing simplicity, good thermal shock resistance, rapid start-up/shut-down time and excellent power cycling.3 Additionally, current technology is progressing towards microtubular stacks (MT-SOCF) owing to the enhanced volumetric power density, inversely proportional to diameter.4,5 On this matter, majority of recent works are heading for electrode-supported designs with thinner electrolytes to reduce the operation temperature, and thereby extending the range of SOFCs applications into mobile and portable fields.3 Specifically, anode-supported 
configurations have been on particular interest to overcome the issues associated with the consolidation of a dense electrolyte layer on the traditionally used cathode-

supports.6-10 Nevertheless, in order to expedite the commercialization of MT-SOFCs systems, cell costs need to be remarkably reduced. In this way, the fabrication method of the support still remains as one of the major challenges, as well as the improvement of overall cell efficiency and reliability.11

Several shaping techniques have been commonly applied to produce tubular supports such as slip casting, isostatic pressing or powder pressing, although extrusion processes are hitherto preferred.4,5,11 Within this context, Powder Extrusion Moulding (PEM) is highlighted a fast near-net-shape and cost-effective manufacturing method to produce tubular geometries. Similarly to Powder Injection Moulding techniques (PIM), PEM forming technology combines the advantages of plastic extrusion moulding and conventional powder metallurgy. PEM processes are usually composed of four steps: mixing, extrusion moulding (instead of injection), debinding and sintering. In practice, the extrusion step consists of forcing a feedstock (i.e. a mixture of powders and binder components) through a fixed shape nozzle to obtain constant cross-sections. The success of the process will rely largely on the powders; i.e. particle size, particle size distribution, shape and surface characteristics. This is not only because they strongly affect the flow behaviour of the mixtures, but also may play a decisive role in the subsequent extrusion steps.12 Beyond the used powders, the selection of a suitable binder, along with the development of formulations with a relatively low viscosity and high solid content, are crucial to attain optimal flow properties. In addition, concerning PEM of thinwalled profiles, the flow behaviour is a key aspect for shape retention.6,13 On this regard, water-based pastes processed at room temperature have been commonly employed in MTSOFCs fabrications with successful results.6,8-11 However, to the best of our knowledge, there are few works involving thermoplastic-based melts.13-16

The main scope of this contribution is to investigate the feasibility of the fabrication of Ni-YSZ tubes by thermoplastic extrusion moulding to be finally used as anode-supports in SOFCs. Typically, highly porous Ni-YSZ cermets with porosity levels around $40-50$ vol. $\%$ are required to ensure an efficient three-phase-boundary (TPB) among electrode, electrolyte and gas phase.17 Commonly, carbon black, flake graphite, spherical polymethyl methacrylate, rice starch or sucrose have been used to produce similar porous structures.18-22 In this work, the use of corn starch as a pore forming agent in an extrusion process is addressed for the first time. The planned research work entails the mixture of dissimilar powders in a relatively wide range of sizes and shapes, which constitutes a particular issue not very common in conventional PEM. Thus, to evaluate the influence of particle size and particle size distribution on the extrusion process and final cermet microstructure, two different NiO powders were tested. The experimental work was carried out on the basis of past experience with successful implementation of PIM and PEM technologies to different types of materials such as alumina, 23 duplex-stainless steels, 24 ferritic stainless steels, 25 high speed steels, 16 YSZ, 26,15 and also on the processing of Ni-YSZ tubular anodes by cold isostatic pressing (CIP).5,27,28

\section{Experimental}

Submicron zirconia stabilized with 8 mol\% of yttrium oxide ceramic powder (TZ-8YS, Tosoh Corporation) with a median particle size (D50) of $0.9 \mu \mathrm{m}$ was used in combination with two nickel oxide types, a coarse $\mathrm{NiO}$ ( $\mathrm{NiO}$ grade $\mathrm{A}, \mathrm{INCO}$ ) with $\mathrm{D} 5 \mathrm{O}=8 \mu \mathrm{m}$ and a fine $\mathrm{NiO}$ (GNO grade 
F, Hart Materials) with D50 $=0.7 \mu \mathrm{m}$. Commercial corn starch (Cst) was purchased to be used as a pore forming agent. The scanning electron microscopy (SEM) images showing the irregular morphology of these powders are presented in Fig. 1. Equally, particle size distributions obtained by laser diffraction in a Mastersizer 2000 are plotted in Fig. 2a.

Based on previous studies, 5,27 the $\mathrm{NiO} / \mathrm{YSZ} / \mathrm{Cst}$ ratio was fixed to obtain final cermets with a $\mathrm{Ni} / \mathrm{YSZ}$ ratio of $50 / 50$ in volume and 50 vol.\% of porosity. Taking this fact into account, and considering that the reduction of $\mathrm{NiO}$ to $\mathrm{Ni}$ metal entails a change of volume of $\sim 40 \%$, the calculated ratio between the precursor powders (NiO/YSZ/Cst) was set as 41.5/24.5/34 vol.\%. Cumulative distributions of both coarse and fine NiO/YSZ/Cst mixtures are presented in Fig. $2 \mathrm{~b}$. Likewise, the main particle size parameters derived from these curves are summarized in Table 1. As the Sw parameters of both mixtures are similar, the width of the particle size distribution is assumed to not affect the results.

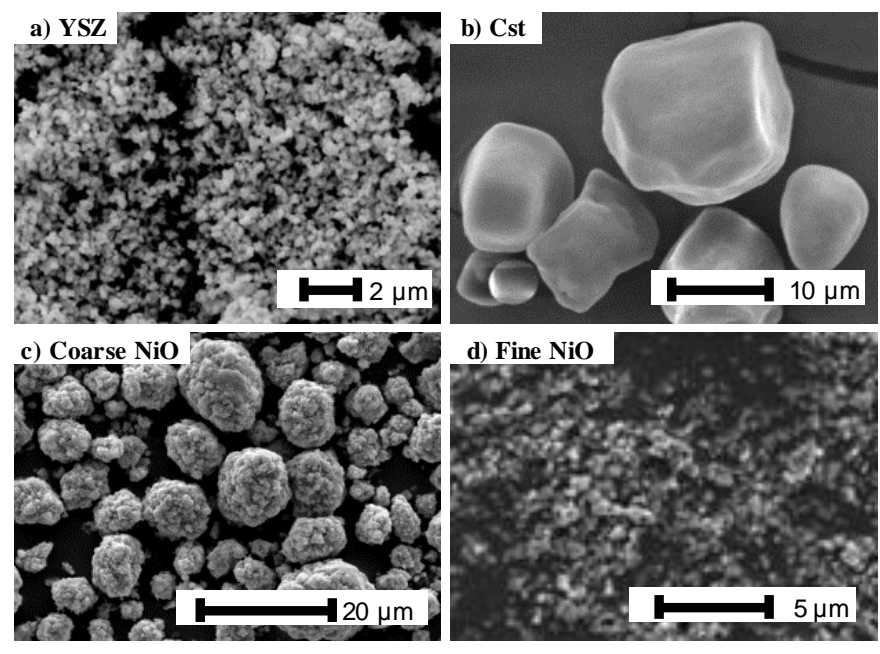

Fig. 1. SEM micrographs of YSZ (a), Cst (b), coarse NiO (c) and fine NiO (d).

The previously reported, and successfully used for PIM26 and PEM15 of YSZ, binder system consist of a thermoplastic multi- component mixture of a strong backbone polymer (polypropylene) (PP, Repsol), a wax to increase flowability (paraffin wax) (PW, Panreac) and a surfactant/lubricant to improve binder-powder interaction and help with tool release (stearic acid) (SA, Panreac). Binder composition and the main characteristics of their components are given in Table 2. Melting points and decomposition temperatures of polymers and additives were obtained by means of thermogravimetric analyses (TGA) and differential scanning calorimetry (DSC) in a Perkin Elmer TGA Pyris1 Perkin and a Elmer Diamond DSC, with a heating rate of $10^{\circ} \mathrm{C} \cdot \mathrm{min}-1$ and nitrogen as purging gas.

The solids were premixed in a Turbula mixer at room temperature. Afterwards, feedstock mixing experiments were performed on a Haake Rheocord 252p mixer with a pair of roller rotor blades. The maximum capacity of the mixing chamber was $69 \mathrm{~cm} 3$. The binder components were added in descending order of molecular weight ( $P P>P W>S A)$. Subsequently, the powder loading was divided into three portions and progressively incorporated. Since one of the main task in PEM is to find an optimum powder-binder ratio, different feedstocks with a solid loading varying in the interval $45-65$ vol.\% were mixed at $180^{\circ} \mathrm{C}$ and $40 \mathrm{rpm}$ up to achieve the steady state torque (乡ss). 

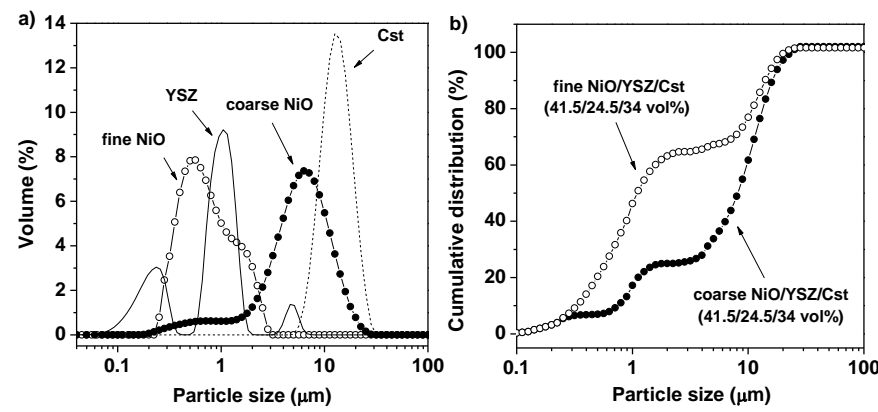

Fig. 2. Particle size distribution curves for the precursor powders (a) and cumulative distribution curves for the coarse and fine NiO/YSZ/Cst mixtures (b).

Table 1. Particle size distribution parameters of coarse and fine NiO/YSZ/Cst mixtures.

\begin{tabular}{lllll}
\hline Powder mixture & $\mathrm{D}_{10}$ & $\mathrm{D}_{50}$ & $\mathrm{D}_{90}$ & $\mathrm{~S}_{\mathrm{w}}{ }^{\mathrm{a}}$ \\
\hline Coarse NiO/YSZ/Cst & 0.73 & 8.12 & 14.10 & 1.99 \\
Fine NiO/YSZ/Cst & 0.32 & 1.08 & 14.30 & 1.55 \\
\hline
\end{tabular}

${ }^{a}$ Width of particle size distribution, $S_{w}=2.56 / \log \left(D_{90} / D_{10}\right)$

Table 2. Characteristics of the binder components.

\begin{tabular}{llllll}
\hline Component & $\begin{array}{l}\text { Content } \\
(\text { vol.\%) }\end{array}$ & $\begin{array}{l}\rho \\
\left(\mathrm{g} \cdot \mathrm{cm}^{-3}\right)\end{array}$ & $\begin{array}{l}\mathrm{T}_{\mathrm{m}}{ }^{\mathrm{a}} \\
\left({ }^{\circ} \mathrm{C}\right)\end{array}$ & $\begin{array}{l}\Delta \mathrm{H}_{\mathrm{m}}{ }^{\mathrm{b}} \\
\left(\mathrm{J} \cdot \mathrm{g}^{-1}\right)\end{array}$ & $\begin{array}{l}\Delta \mathrm{T}^{\mathrm{c}} \\
\left({ }^{\circ} \mathrm{C}\right)\end{array}$ \\
\hline $\mathrm{PP}$ & 50 & 0.89 & 163.8 & 100.5 & $280-480$ \\
$\mathrm{PW}$ & 46 & 0.91 & 56.8 & 145.0 & $190-360$ \\
$\mathrm{SA}$ & 4 & 1.01 & 73.7 & 169.5 & $190-300$
\end{tabular}

a Melting point. ${ }^{\mathrm{b}}$ Melting enthalpy. ${ }^{\mathrm{c}}$ Decomposition temperature.

The processed feedstocks are referenced in Table 3 by their powder loading and the type of $\mathrm{NiO}$ incorporated. For example, CP45 and FP45 are the feedstocks with coarse and fine NiO, respectively, and containing solid loadings of $45 \mathrm{vol} . \%$. The mixing behavior was analyzed by means of torque versus mixing time curves. Equally, feedstocks homogeneity was evaluated through the analysis of the steady state torque $(\xi s s)$ and density measurements. The latter were performed in a Micrometrics AccuPyc 1330 helium pycnometer, testing three representative portions of the same batch. The rheological characterization of the feedstocks was conducted in a ThermoHaake Rheoflixer capillary rheometer with temperature control of $\pm 1^{\circ} \mathrm{C}$ and a die of $1 \mathrm{~mm}$ of diameter and $30 \mathrm{~mm}$ of length.

The extrusion of the tubular shapes was performed in a Haake PolyLab OS single-screw. The tubes were vertically extruded through a home-designed nozzle of $4 \mathrm{~mm}$ outer diameter and 2 $\mathrm{mm}$ inner diameter (i.e. wall thickness of $1 \mathrm{~mm}$ ). Extruded parts were immediately cooled 
down in water at $20^{\circ} \mathrm{C}$ acquiring enough strength to keep their geometrical form as a green part and avoiding section reduction and necking. The distance from the nozzle to cooling water was set at $30 \mathrm{~mm}$. Temperatures of different parts of extruder (from feed area to nozzle) and extrusion rate were optimized to obtain defect-free microtubes with constant cross-section and maximal length.

A combination of solvent and thermal debinding was applied for binder removal. This debinding process has been previously reported with successful results for Al2O323 and YSZ15,26 parts. An immersion in a bath of $n$-heptane $\left(60^{\circ} \mathrm{C}\right)$ was used for solvent debinding, monitoring the weight loss to obtain the optimal immersion time. The thermal cycle was designed on the basis of TGA experiments using a Perkin-Elmer TGA Pyris1.

Table 3. Composition of the feedstocks (vol.\%).

\begin{tabular}{lllllll}
\hline Feedstock tag & YSZ & NiO & Cst & PP & PW & SA \\
\hline CP45, FP45 & 11.02 & 18.68 & 15.30 & 27.50 & 25.30 & 2.20 \\
CP50 & 12.25 & 20.75 & 17.00 & 25.00 & 23.00 & 2.00 \\
CP55, FP55 & 13.47 & 22.83 & 18.70 & 22.50 & 20.70 & 1.80 \\
CP60, FP60 & 14.70 & 24.90 & 20.40 & 20.00 & 18.40 & 1.60 \\
FP65 & 15.92 & 26.98 & 22.10 & 17.50 & 16.10 & 1.40 \\
\hline
\end{tabular}

TGA analyses were performed from room temperature to $700{ }^{\circ} \mathrm{C}$ under a $100 \mathrm{~mL} \cdot \mathrm{min}-1$ air flow and a heating rate of $10^{\circ} \mathrm{C} \cdot \mathrm{min}-1$. The effectiveness of the debinding process was confirmed through carbon elemental analyses of the so-called brown parts using a LECO instrument.

Sintering process was carried out immediately after the debinding step. The tubes were placed horizontally on Al2O3 crucibles and sintered at $1400{ }^{\circ} \mathrm{C}$ (heating ramp of $4{ }^{\circ} \mathrm{C} \cdot \mathrm{min}-1$ ) for 2 hours under static air. Anodes were reduced at $800^{\circ} \mathrm{C}$ under pure humidified $\mathrm{H} 2$ flow. Microstructural characterization of polished cross-section samples was performed using a field emission scanning electron microscope (Merlin FE-SEM, Carl Zeiss). Hg-porosimetry was conducted in a Quantachrome Poremaster porosimeter. DC conductivity was measured by the four point probe method at $20^{\circ} \mathrm{C}$ using a Princeton Applied Research VSP potentiostat/galvanostat. 28,29

\section{Results and discussion}

\section{Mixing and compounding.}

Monitoring the evolution of rotor torque values with mixing time is a common and helpful method to evaluate the effectiveness of the compounding process. Counting on this, all the compositions were successfully mixed, except the feedstock labelled as CP60. In this case, torque values exceeded the maximum allowable for the equipment after $\sim 1$ hour of mixing. In turn, once the chamber was opened the separation between the powder and the binder was quite noticeable. In Fig. 3 the torque as a function of mixing time is presented for all the 
planned feedstocks. Typically, local maximums related with the progressive addition of the powder loading are observed in torque curves, following by a gradual decrease towards the final steady state ( $(s s)$. In case of FP45, FP55 and FP60 feedstocks these local maximums are markedly lower, compare to the registered sharp rises in torque values for CP45, CP50, CP55 and FP65 mixtures. On this regard, both the solid loading and the power-binder system properties may influence the flow of the melts and, in consequence, the reached torque level. This point will be discussed in more detail further below.

According to Fig. 3, the optimum mixing time (i.e. the necessary to achieve the steady state) is established at 120 min for feedstocks with coarse $\mathrm{NiO}$, while fine $\mathrm{NiO}$ containing feedstocks reach the steady state in a mixing time below $60 \mathrm{~min}$. Fig. $4 \mathrm{~b}$ represents the average $\xi s s$ values and their standard deviations over the last 5 minutes of mixing; i.e. between 115(55) and 120(60) min for feedstocks with coarse (fine) NiO. Equally, the upper and lower $\xi$ ss values are also plotted as an indirect tool to evaluate the homogeneity of the feedstocks. As expected, $\xi s s$ values are higher when using high powder concentration feedstocks, since the greater friction effects among the hard powder particles hinder the flow of the melts. On the other hand, the coarse NiO containing feedstocks exhibit significantly higher $\xi$ ss values $(4.8-13.8 \mathrm{~N} \cdot \mathrm{m})$ after 120 min of mixing than those with fine $\mathrm{NiO}(0.2-1.7 \mathrm{~N} \cdot \mathrm{m})$ after $60 \mathrm{~min}$. Therefore, it is evident an increased resistance on the rotor blades when mixing coarse instead of fine $\mathrm{NiO}$ powders, suggesting noticeable differences in the viscosity of the melts. Moreover, a change in the slopes of two straight lines fitting the experimental measurements is also deduced. Some authors associate this observation with the optimal solid loading. 30 In this sense, as firstly reported by German and Bose,12 the optimal solid loading should be at least $5 \%$ lower than the critical powder volume content (CPVC); i.e. the volume of binder is insufficient to embed all the particles and fill the remaining free volume. Taking this into account, the CPVC for feedstocks with coarse and fine $\mathrm{NiO}$ should be within the interval 52.6-57.9 and 63.2-68.4 vol.\%, respectively. These estimations are rather consistent with the unsuccessful mixing experience noted for the CP60 feedstock, since it is strongly believed that the powder loading exceeds the CPVC.
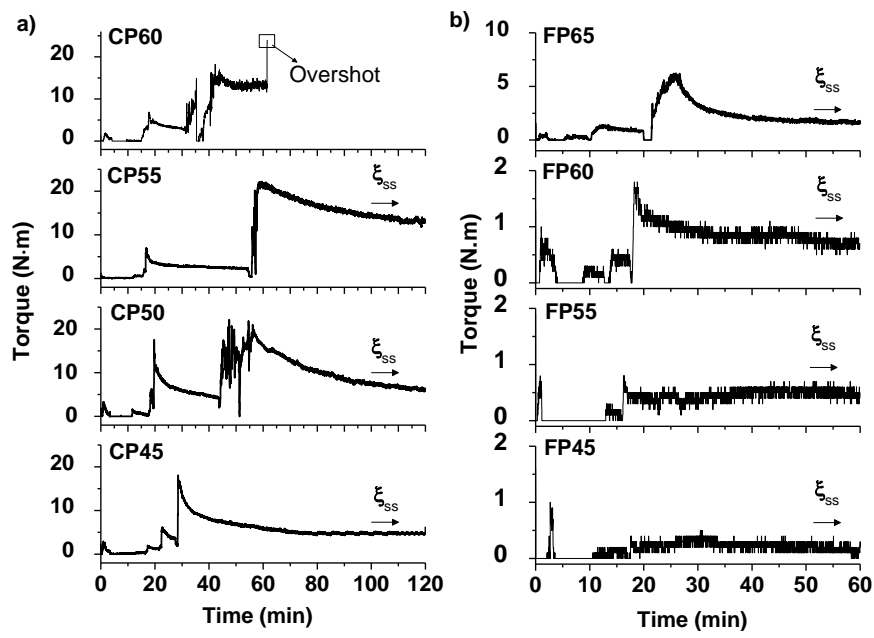

Fig. 3. Torque as a function of mixing time at $180^{\circ} \mathrm{C}$ and $40 \mathrm{rpm}$ for feedstocks with coarse (a) and fine (b) $\mathrm{NiO}$ and different powder loadings.

Fine NiO containing feedstocks are presumably more homogeneous than feedstocks with coarse $\mathrm{NiO}$ owing to the registered higher variability in $\xi s s$ values over the last $5 \mathrm{~min}$ of mixing. 
Since the homogeneity of the feedstock has a major influence on the success of the process (helping to minimize segregation during extrusion and promoting isotropic shrinkage after debinding and sintering),12 pycnometric densities are also shown in Fig. $4 \mathrm{~b}$ along with the theoretical values determined by the rule of mixtures. Coarse $\mathrm{NiO}$ containing batches exhibit deviations systematically greater than batches with fine $\mathrm{NiO}$, especially at high solid contents. Accordingly, greater heterogeneities within coarse NiO containing melts are suspected as a result of the less efficient mixture. In spite of this, the results highlight a relatively good correlation between the experimental measurements and the theoretical values for all the processed feedstocks. However, it is worth to note that the density of fine $\mathrm{NiO}$ containing feedstocks is always slightly lower than the expected theoretical values. Thus, assuming that no material is lost during the mixing, this observation may be associated with the greater tendency of finer particles to form small clusters of agglomerated particles. On the other hand, a relatively abrupt decrease in density due to the formation of voids within the feedstocks bulk is commonly used to estimate the CPVC in PEM production. Nevertheless, no clear evidences on this regard were found.
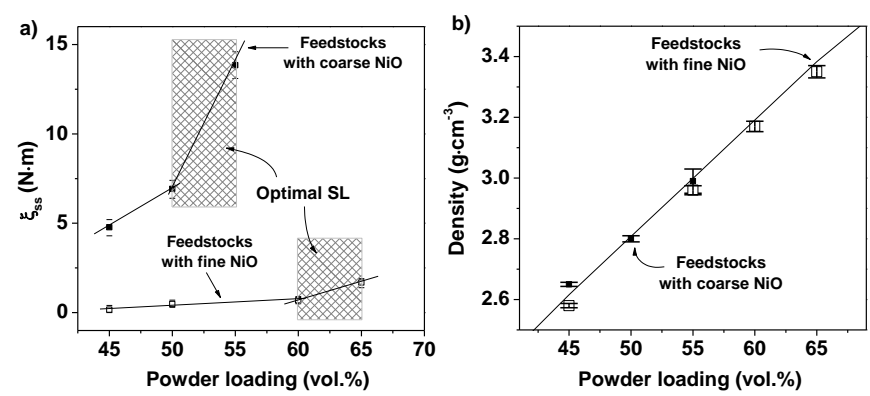

Fig. 4. Steady state torque ( $(s s)$ (a) and pycnometer density (b) in function of the powder loading for feedstocks with coarse and fine NiO. Horizontal marks in (a) correspond to the upper and lower $\xi s s$ values. Theoretical density obtained from the rule of mixtures is plotted in (b) as a solid line.

Mixing results may turn out somehow contraries to what it is expected, since a worsening in the mixing behavior is obtained for feedstocks with a higher D50 (coarse NiO containing feedstocks); i.e. exhibit sharp rises in torque level during mixing time, need longer homogenization times and reach higher $\xi s s$ values. In consequence, a lower optimal solid loading is achieved. Theoretically, randomly packed systems presenting higher D50 (i.e. lower surface area) entail a higher amount of binder in order to improve the flowability (assuming a similar width of particle size distributions as it is settled on Table 1).12 Thus, a better behavior during the mixing step is expected for these systems. On the other hand, a slightly worsening of the flow would be reasonable when dealing with irregular particles as a result of a major immobilization of binder in the interstices among the coarser particles. Despite of this fact, the significant differences observed between the coarse and fine NiO containing feedstocks suggest the consideration of additional aspects, which will be discuss further in the section below.

\section{Feedstock rheology.}

The rheological properties of the feedstocks are crucial to determine the extrudability. Moreover, in thin-walled tube extrusion, rheological behavior is conclusive to avoid collapse. The evolution of the viscosity with the shear rate at $180^{\circ} \mathrm{C}$ for all the processed feedstocks is 
shown Fig. 5a. Feedstocks with coarse NiO powder, exhibit higher viscosity values than those containing fine $\mathrm{NiO}$ powders, particularly at lower shear rates. This fact is in conjunction with the previously observed mixing behaviour (Fig. 3 and 4a), which revealed significant differences in the steady state torque values ( $\xi s s)$ as a function of the type of $\mathrm{NiO}$ incorporated. Equally, the viscosity of the powder-binder mixtures is found to be quite sensitive to the solid content, especially in the case of fine NiO containing feedstocks. Thereby, a higher solid loading causes a rise in viscosity level due to the major inter-particle interaction. Nevertheless, it should be noted that all the feedstocks, except the CP55, seem to be suitable for extrusion, since they exhibit viscosity values below $1000 \mathrm{~Pa} \cdot \mathrm{s}$ (maximum recommended for PIM and PEM)12,13 between 100 and 10000 s- 1.
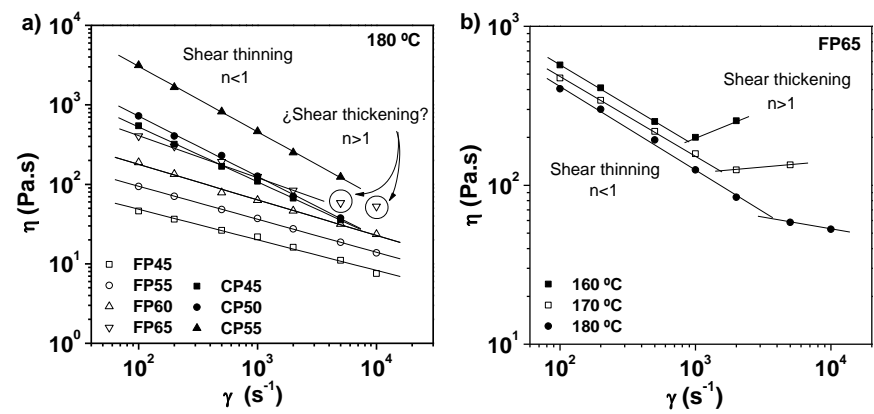

Fig. 5. Viscosity curves at $180^{\circ} \mathrm{C}$ for feedstocks with coarse and fine $\mathrm{NiO}$ and different powder loadings (a). Viscosity curves at 160, 170 and $180^{\circ} \mathrm{C}$ for FP65 feedstock (b). Solid lines in (b) represent the fitting curves according to the power law (equation 1 ).

The viscosity-dependence on shear rate can be approximated by the power law:12

$\eta=\mathrm{k} \cdot \dot{\gamma}^{(\mathrm{n}-1)}$

where $\eta$ is the viscosity of the mixture, $\dot{\gamma}$ the shear rate, $\mathrm{n}$ the power law flow behaviour index and $k$ the consistency coefficient. The experimental data in Fig. $5 b$ are well fitted to equation (1) with good correlation factor ( $2>0.99$ ). As a general rule, all the mixtures exhibit a shearthinning or pseudoplastic $(n<1)$ behavior between 100 and $10000 s-1$; i.e. viscosity decreases as shear rate increases. However, a shear- thickening behavior $(n>1)$ is suspected for FP65 mixture at high shear rates; i.e. viscosity increases as shear rate increases. Subsequent viscosity measurements at 160 and $170^{\circ} \mathrm{C}$ were performed (Fig. 5b) to highlight this behavior. From these experiments, the transition from thinning to thickening behavior is switched to lower shear rates when the temperature decreases. Some authors relate the observation of a shear-thinning response at high shear rates with the breakage of a theorized network structure within the melt.31 In consequence, the rheological response becomes dominated by hydrodynamic binder-particle interactions, which favor the orientation of the polymeric chains and particles in the flow direction.32,33 On the other hand, depending on binder wetting mechanism and especially when irregularly shaped particles are involved, the shear-thinning may turn into shear-thickening behavior at high powder concentrations.34 Barnes et al. reported shear-thickening flow at high shear rates as a function of filler concentration, particle size distribution and viscosity of the melts. These authors proposed the disruption of the layers formed in the pseudoplastic flow region as the main cause of thickening. 35 However, there is still certain controversy about the origin of this behavior and some experimental artifacts such as wall-slip and wall-depletion phenomena must be accounted for.36,37 On this way, a large dependence of viscosity on the concentration of solids usually leads to significant slip effects as it was pointed out by Hausnerova33. Otherwise, the feedstocks used in this work contain 
corn starch (Cst), which is well-known by its shear-thickening response at high shear rates. Therefore, the higher Cst content of the FP65 mixture (22.10 vol.\%) could also play a key role. However, to settle this discussion further investigation may be needed, involving additional rheological tests to characterize possible wall-slip and wall-depletion phenomena and determine corn starch involvement. Nevertheless, it is assumed that shear-thickening does not affect the overall purpose of this work, since common shear rates in extrusion processes vary from 10 to $1000 \mathrm{~s}-1$.

The theorized network structure within the melt at low shear rates, which breaks only when a minimum force is applied, is supposed to be closely related with the packing conditions of the solids. To a better understanding of this network structure, the widely accepted HerschelBulkley model (equation 2) is a valuable method to estimate the yield stress.12

$\tau=\tau_{\mathrm{o}}+\mathrm{k} \cdot \dot{\gamma}^{\mathrm{n}}$

where $\tau$ and $\tau_{-} \mathrm{o}$ are the shear stress and the yield stress, respectively. The experimental data were in a relatively good agreement ( $r 2>0.97)$ with the model $(2)$ as it is shown in Fig. 6 a. Similarly, Fig. $6 \mathrm{~b}$ illustrates a clear increasing tendency of yield stress with the concentration of solids for both fine and coarse containing $\mathrm{NiO}$ feedstocks. Unlike what it would be firstly expected (i.e. finer particles entail greater yield values due to their larger surface area and higher inter-particle friction),12 feedstocks with coarser particles reach greater yield stress values. Nevertheless, previous works have reported similar effects, indicating significant values of yield stress for systems with large particles due to steric hindrances.38 On this regard, taking into account the significant dissimilarity between the interacting coarse particles (see coarse $\mathrm{NiO}$ and Cst powders in Fig. 2a), these steric hindrances contribution may play a critical role. Therefore, higher yield stress in feedstocks with coarse $\mathrm{NiO}$ may be reasonable, hindering the optimal packing of the theorized network structure within the melt by steric limitations. On the contrary, a theorized network structure at low shear rates in which inter-particle friction effects favour the packing is supposed for feedstocks with fine NiO. These assumptions can equally be extrapolated to the mixing behaviour, suggesting an explanation for the observed differences.
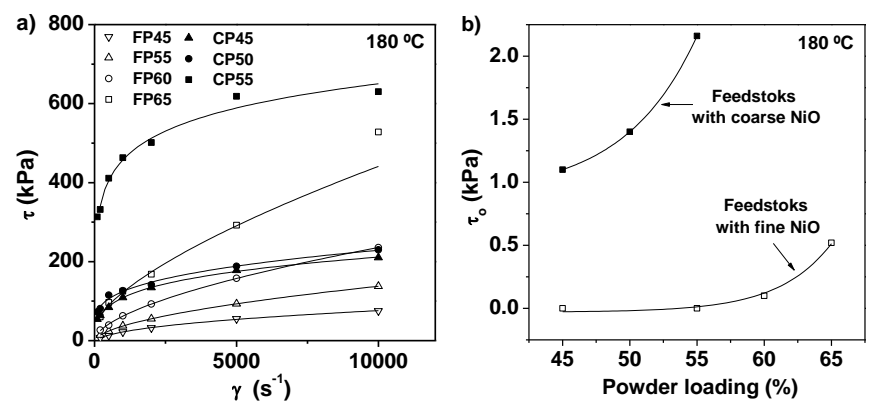

Fig. 6. Shear stress curves at $180^{\circ} \mathrm{C}$ for feedstocks with coarse and fine $\mathrm{NiO}$ and different powder loadings. Calculated yield stress in function of the powder loading at $180^{\circ} \mathrm{C}$ (b). Solid lines in (a) correspond to the fitting curves according to the Herschel-Bulkley model (equation 2).

Pseudoplastic behaviour is often sought in extrusion processes. However, some common defects such as swelling are usually related with a high pseudoplastic character; i.e. low powerlaw index. The power-law index (equation 1 ) for feedstocks containing coarse $\mathrm{NiO}$ is found to be $0.30,0.26$ and 0.17 for $\mathrm{CP} 45, \mathrm{CP} 50$ and $\mathrm{CP} 55$, respectively. The mixtures with fine $\mathrm{NiO}$ exhibited a substantially lower level of pseudoplasticity, since the power-law indexes 
calculated in the shear thinning region are higher; i.e. $0.61,0.58,0.55$ and 0.53 for FP45, FP55, FP60 and FP65, respectively. Furthermore, regardless of the incorporated $\mathrm{NiO}$, the presented results indicate a slightly increase of the pseudoplastic character with the powder loading.

The rheological behaviour of the feedstocks as a function of the temperature may compromise the success of the extrusion process. The temperature effect on viscosity can be figured out in terms of thermal expansion. In this way, as temperature increases, a binder thermal expansion may occur causing a rise in the free volume. Therefore, a reduction in viscosity level is commonly expected due to an enhanced mobility. This temperature dependence is shown in Figure 7 at 100 and $1000 \mathrm{~s}-1$. The exposed curves obey an Arrhenius behaviour according to the equation $3: 12$

$\eta=A \cdot \exp \left(\frac{E}{R T}\right)$

where $\mathrm{A}$ is a constant, $\mathrm{E}$ the activation energy, $\mathrm{R}$ the universal gas constant and $\mathrm{T}$ the absolute temperature. The calculated $\mathrm{E}$ values are summarized in Table 5 . It should be mentioned that temperatures below $180^{\circ} \mathrm{C}$ were barely enough to promote the flow of the feedstocks with coarse $\mathrm{NiO}$, since an erratic variation of the viscosity was detected. Consequently, these measurements were rejected to estimate $E$ values. Thus, according to these results, the activation energy of the feedstocks decreases as the shear rate increases. Hence, when the solids and the polymeric chains are likely forming an entangled structure (typical of low shear rate regimes) the temperature may play a key role in viscosity reduction. Beyond the shear rate, the activation energy is also affected by the solid loading. On one hand, the activation energy for the feedstocks with coarse $\mathrm{NiO}$ decreases as the solid loading increases. On the contrary, a rise in the activation energy with the solid content is observed for fine NiO containing feedstocks, although a disruption at 65 vol.\% and $100 \mathrm{~s}-1$ is observed. Even though there is some controversy on how the activation energy is affected by the solid content, two main mechanisms may be differentiated. Some authors, as firstly reported by Shenoy, 39 claim a reduction on activation energy at higher filler contents. Their explanation is based on the fact that the fillers provide very little free volume change with temperature in relation to the binder. On the contrary, as firstly proposed by German, 12 the decrease in the relative rate of viscosity should be faster (i.e. greater $E$ value) at higher filler contents due to the superimposed change in the volume fraction of powder. The last suggestion is based on the differences between binder and powder thermal expansion coefficients. Taking these two mechanisms into account, the trend proposed by Shenoy may explain the behaviour of coarse $\mathrm{NiO}$ containing feedstocks, while feedstocks with fine NiO seem to follow the tendency suggested by German and Bose. However, the superimposed change in the volume fraction of powder seems to fail when the shear rate is not high enough for orientation and ordering (disruption at 65 vol.\% and $100 \mathrm{~s}-1$ ).

It is worth to note that $\mathrm{E}$ values are significantly higher for fine $\mathrm{NiO}$ containing feedstocks. The explanation of this fact may be associated to the previously mentioned concept of the network structure. Thereby, it is should be considered that the steric hindrances acting in coarse containing $\mathrm{NiO}$ feedstocks can not be easily counteracted by increasing temperature effects, reducing the obtained $\mathrm{E}$ values. On the contrary, temperature may play a critical role regarding flow behavior (higher $E$ values) when the viscosity is rather dominated by the inter-particle and binder-particle friction effects (feedstocks with fine $\mathrm{NiO}$ ). 

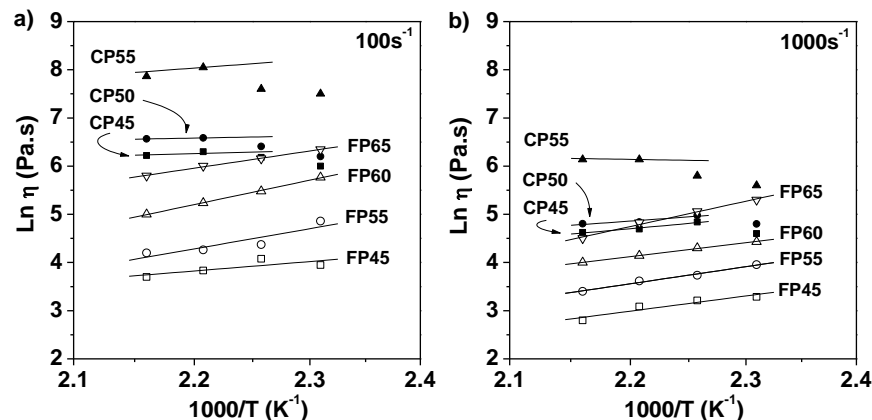

Fig. 7. Temperature dependence of viscosity at 100 (a) and $1000 \mathrm{~s}-1$ (b) for feedstocks with coarse and fine $\mathrm{NiO}$ and different powder loadings. Solid lines in (a) and (b) correspond to the fitting curves according to the equation 3.

Table 5. Activation energy at 100 and $1000 \mathrm{~s}-1$ for feedstocks with coarse and fine $\mathrm{NiO}$ and different solid loadings.

\begin{tabular}{llllllll}
\hline Shear rate $\left(\mathrm{s}^{-1}\right)$ & CP45 & CP50 & CP55 & FP45 & FP55 & FP60 & FP65 \\
\hline 100 & 8.6 & 6.7 & 1.2 & 23.6 & 35.2 & 43.2 & 25.4 \\
1000 & 1.8 & 1.3 & 1.1 & 16.4 & 27.4 & 30.4 & 38.6 \\
\hline
\end{tabular}

Finally, in order to calculate the CPVC from a rheological point of view and compare the results with the predictions based on torque measurements, the rheological model proposed by Reedy40 has been applied. Accordingly, the critical solid loading is estimated by the following equation:

$\eta_{\mathrm{m}} \cdot \Phi_{\mathrm{L}}=\eta_{\mathrm{m}} \cdot\left(\Phi_{\mathrm{L}}\right)_{\mathrm{C}}+\eta_{\mathrm{L}} \cdot\left(1-\left(\Phi_{\mathrm{L}}\right)\right)_{\mathrm{C}}$

where $\eta_{\mathrm{m}}$ is the feedstock viscosity, $\Phi_{\mathrm{L}}$ the binder volume, fraction, $\left(\Phi_{\mathrm{L}}\right)_{\mathrm{C}}$ the critical binder volume fraction, $\eta_{\mathrm{L}}$ the binder viscosity and $\Phi_{\mathrm{C}}$ the critical solid loading calculated as $\Phi_{\mathrm{C}}=$ $1-\left(\Phi_{\mathrm{L}}\right)_{\mathrm{C}}$. Table 6 presents the critical solid loading at 100 and $1000 \mathrm{~s}^{-1}$. The regression coefficients are higher than 0.98 in all the cases and the calculated $\Phi_{C}$ values are in concordance with those predicted on Fig. 4a. The markedly higher CPVC is proposed to be closely linked to the improved packing mechanism achieved with fine NiO/YSZ/Cst mixture, in which steric hindrances among the coarser particles are avoided. Therefore, considering both torque measurements and rheological tests, the optimal solid loading for feedstocks with coarse and fine $\mathrm{NiO}$ is established at 50 and 65 vol\%, respectively.

Table 6. Critical solid loading for feedstocks with coarse and fine NiO.

\begin{tabular}{lllll}
\hline Shear rate $\left(\mathrm{s}^{-1}\right)$ & \multicolumn{3}{l}{ Coarse $\mathrm{NiO}$} & \multicolumn{2}{l}{ Fine NiO } \\
\cline { 2 - 5 } & $\Phi_{\mathrm{C}}(\%)$ & $\mathrm{R}^{2}$ & $\Phi_{\mathrm{C}}(\%)$ & $\mathrm{R}^{2}$ \\
\hline 100 & 57 & 0.994 & 67 & 0.999 \\
1000 & 58 & 0.988 & 69 & 0.999 \\
\hline
\end{tabular}




\section{Extrusion and debinding.}

Thermoplastic extrusion in vertical direction and subsequent cooling in water below the nozzle resulted effective to produce free-defects and non-deformed tubes with $4 \mathrm{~mm}$ of diameter and $1 \mathrm{~mm}$ of nominal wall thickness. One of the main disadvantages of vertical extrusion is the narrowing of the tubes, since the weight loads the area just below the nozzle and favors a plastic deformation. In turn, these narrowing effects increase with the temperature of the mixture, especially for coarse $\mathrm{NiO}$ containing tubes. On the contrary, low extrusion temperatures lead to simultaneous increases in both surface roughness of the extruded tubes and wear inside the extrusion chamber, at the same time the flow is usually interrupted. Consistently, the temperature was kept as low as possible, and the extrusion rate was slightly increased (when needed) to enhance the flow. Thus, an optimum temperature profile from the feed to the nozzle of $160-170{ }^{\circ} \mathrm{C}$ and $170-180^{\circ} \mathrm{C}$ was selected for coarse and fine NiO containing feedstocks, respectively. The rate of tube extrusion was chosen within the interval $15-30 \mathrm{~mm} \cdot \mathrm{s}-1$. A slight increase on the surface roughness (using both coarse and fine $\mathrm{NiO}$ containing feedstocks), along with a lower narrowing at higher solid contents (using fine $\mathrm{NiO}$ containing feedstocks) were obtained. The best results were found for tubes extruded with CP50 and FP65 formulations. The observed reduction in the extruded tubes diameter with a length of $15 \mathrm{~mm}$ was lower than 0.15 (CP50) and $0.07 \mathrm{~mm}$ (FP65). Scanning electron microscopy (SEM) images of extruded tubes in the so-called "green stage" are shown in figure 8 along with a representative photograph of their overall aspect. NiO, YSZ and Cst particles seem to be homogeneously distributed within the binder in both cases. Nevertheless, the formation of some agglomerates or certain heterogeneities may not be fully rejected.

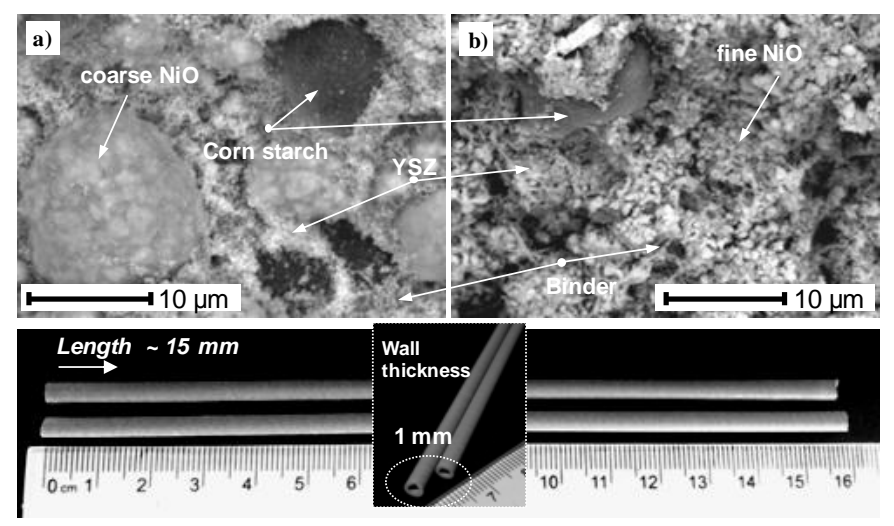

Fig. 8. SEM micrographs (BSE mode) at $x 6500$ showing the microstructure of extruded tubes with CP50 (a) and FP65 (b) mixtures. Photograph of extruded tubes (bottom).
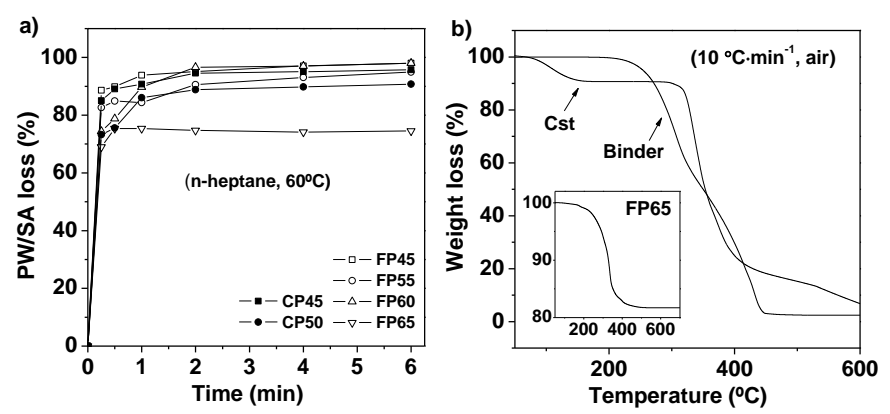

Fig. 9. Weight percentage of PW/SA removed as a function of the immersion time in $n$ heptane at $60^{\circ} \mathrm{C}$ for feedstocks with coarse and fine $\mathrm{NiO}$ and different powder loadings (a). 
TGA curves at $10^{\circ} \mathrm{C} \cdot \min -1$ for the binder and Cst (b). The inset in (b) represents the TGA curve of a FP65 part.

Binder removal was carried out by the combination of two different processes, solvent ( $\mathrm{n}$ heptane) and thermal debinding. The former is beneficial to prevent the formation of cracks, since interconnected channels for helping gas evacuation in the subsequent thermal decomposition step are generated. Fig. 9a illustrates the PW/SA losses over time for the extruded parts. A worsening of the extraction was detected at high solid contents (CP50 and FP65), since channels generation for solvent access and its subsequent diffusion (from the core to the surface) was limited. No remarkable differences were found in solvent behavior as a function of the $\mathrm{NiO}$ incorporated. The best results were obtained for extruded tubes with CP45, FP45, FP50 and FP55 feedstocks, showing an extracted amount of PW and SA above 90 $\%$ after 2 hours of immersion.

Thermal debinding, designed by means of TGA analyses, allowed the complete degradation of the organic part. The elimination of these components occurred gradually in a relatively wide temperature range $\left(190\right.$ to $480^{\circ} \mathrm{C}$ ), which undoubtedly favored the thermal elimination step. Fig. $9 \mathrm{~b}$ shows the thermal degradation of the Cst and the binder, along with a typical TGA curve of a extruded part (inset). As seen, Cst is burned out in two steps after the initial water decomposition. The first weight loss $\left(280-365^{\circ} \mathrm{C}\right)$ is associated with long chain scission and the second $\left(365-530^{\circ} \mathrm{C}\right)$ involves decomposition of the glucose ring. 41 On the other hand, the weight loss experienced by the binder between $190-360$ and $350-500^{\circ} \mathrm{C}$ are ascribed to the degradation of PW+SA and PP, respectively. As expected, the total weight loss percent of the extruded parts corresponded to the total organic content. Particularly, the observed weight loss percent for FP65 (18.3 wt.\%) is very similar to the theoretical removable content (i.e. 4.8, 4.23, 0.42 and $9.8 \mathrm{wt} \%$ of PP, PW, SA and Cst, respectively). The designed heating profile basically followed the stages outlined by the degradation of the removable parts. The whole cycle took 10 hours. In order to avoid long cycles and time-consuming debinding steps a relatively quick heating rate was selected for temperatures below $190^{\circ} \mathrm{C}$ (i.e. $5^{\circ} \mathrm{C}$-min-1 was fixed as a top value to prevent cracking) followed by a plateau of 1 hour. Between 190 and 300 ${ }^{\circ} \mathrm{C}$ a slower heating rate of $3{ }^{\circ} \mathrm{C} \cdot \mathrm{min}-1$ was chosen to degrade residual low molecular weight components. Next, temperature was kept at $300^{\circ} \mathrm{C}$ for 1 hour. Between 300 and $700{ }^{\circ} \mathrm{C}$, where the decomposition of PP and Cst takes place, a slow rate of $1^{\circ} \mathrm{C} \cdot \mathrm{min}-1$ was programmed to prevent blistering and bloating. Finally, the parts were kept at $700{ }^{\circ} \mathrm{C}$ for 1 hour to assure total degradation of the removable components. The carbon content was systematically lower than $0.02 \%$, regardless of the solid content and the incorporated $\mathrm{NiO}$.

\section{Microstructure and final properties.}

The microstructure of $\mathrm{CP} 50$ and $\mathrm{FP} 65$ samples sintered in air at $1500{ }^{\circ} \mathrm{C}$ and reduced in pure $\mathrm{H} 2$ at $800^{\circ} \mathrm{C}$ are shown in Fig. 10 . The microstructure observed for the fine $\mathrm{NiO}$ sample shows a much thinner and interconnected Ni phase (light grey contrast). Pores can be observed in two different morphologies in both samples, ones being 4-6 $\mu \mathrm{m}$ sphere-like pores (caused by the pore former used) whereas the others conforming a submicron connected pore network (generated during the $\mathrm{NiO}$ reduction). As pore size and distribution is critical for a suitable anode performance in tubular SOFC devices, mercury porosimetry experiments were performed. Fig. 10 (bottom) also shows Hg porosimetry studies for coarse and fine NiO containing samples. Total porosity calculated through this technique was $51 \%$ for the sample with coarse $\mathrm{NiO}$ and $43 \%$ for the sample with fine $\mathrm{NiO}$. This difference is originated from the higher extent of densification obtained when sintering the samples containing the finer $\mathrm{NiO}$. 
Values measured for the open porosity were substantially smaller (26 and 34\% for the coarse and fine NiO containing samples, respectively). The fraction of open and close porosity is expected to vary though the life of the material.

The measured DC conductivity was 1600 and $9300 \mathrm{~S} \cdot \mathrm{cm}-1$ for the coarse and fine NiO containing samples respectively, which is in good agreement with the observation of a finer and more connected Ni phase in the sample containing fine NiO. The conductivity value measured for the sample containing fine $\mathrm{NiO}$ powder is close to the maximum theoretical value for this

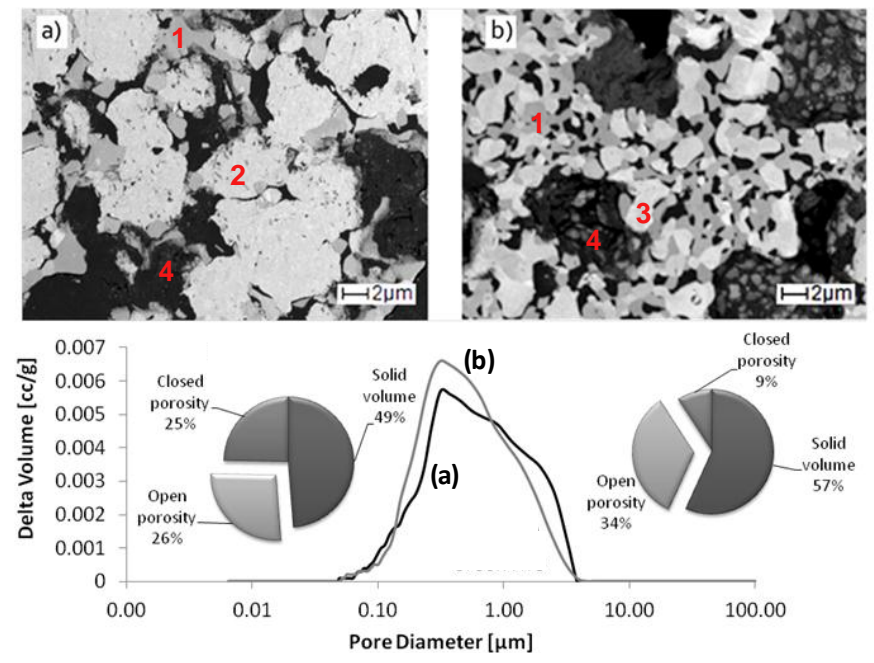

Fig. 10. SEM micrographs and pore size distributions (bottom) for CP50 (a) and FP65 (b) samples sintered at $1500{ }^{\circ} \mathrm{C}$ and reduced in pure $\mathrm{H} 2$ at $800^{\circ} \mathrm{C}$. Numbers in (a) and (b) correspond to YSZ (1), coarse (2) and fine (3) Ni and pores (4) regions.

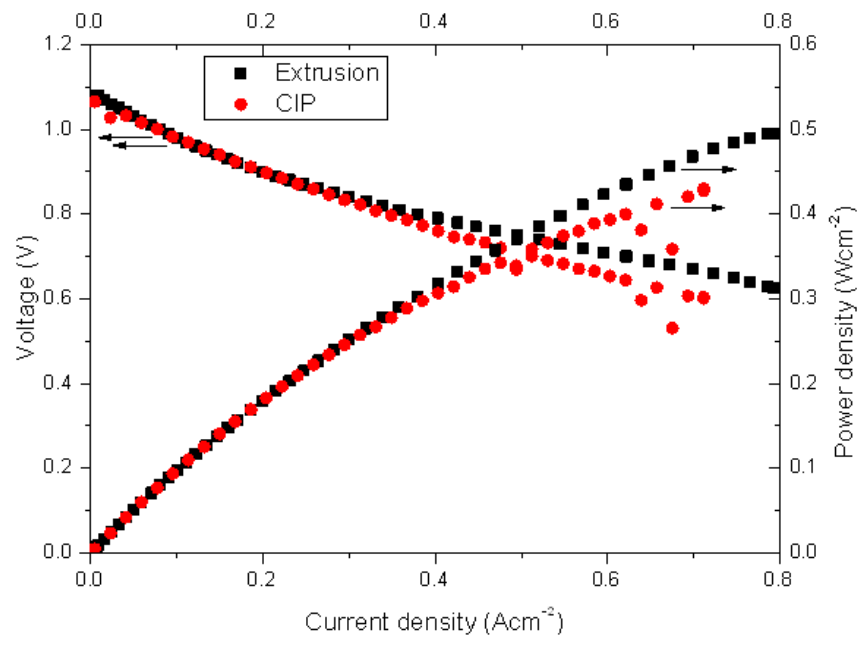

Fig. 11. j-V behavior of a complete Ni-YSZ/YSZ/LSM-YSZ cell supported on an extruded with a $65 \mathrm{vol} \%$ of solid loading (squares) and CIP (circles) fine $\mathrm{NiO}$ based anode at $800^{\circ} \mathrm{C}$.

$\mathrm{Ni}$ volume fraction (12500 S.cm-1). On the other hand the sample with coarse NiO powders presents a rather low conductivity which can be limiting for the final cell performance. In a previous work we have analyzed the performances of anode supported microtubular SOFCs, prepared by this PEM procedure and using fine $\mathrm{NiO}, 42$ as the rest of compositions were discarded for fuel cell fabrication. NiO-YSZ supporting tubes, using YSZ as the electrolyte and LSM-YSZ as the cathode (both deposited by dip-coating) were characterized obtaining very 
competitive power densities: 0.35 and $0.7 \mathrm{~W} \cdot \mathrm{cm}-2$ at $0.5 \mathrm{~V}$ measured at 800 and $850^{\circ} \mathrm{C}$ respectively. The performance shown in Fig. 11 has been increased by enhancing the cathode contacting procedure, yielding power outputs around $0.5 \mathrm{~W} \cdot \mathrm{cm}-2$ at ca. $0.6 \mathrm{~V}$ and $\quad 800$ ${ }^{\circ} \mathrm{C}$. Electrochemical results for an identical cell using the same powders, but fabricated by the CIP process, 27 are also shown for comparison.

\section{Conclusions}

A multi-component binder PP/PW/SA (50/46/4 vol.\%) was successfully used for manufacturing $\mathrm{Ni}$-YSZ thin microtubes by Powder Extrusion Moulding (PEM). Two different NiO powders were tested in order to study the influence of particle size and particle size distribution on the extrusion process and final cermet microstructure. Torque and rheological tests of different feedstock formulations revealed the significant role played by the particle size on the viscosity of the polymer-powder mixtures, and consequently on the extrusion processing. Basing on this study, prepared feedstocks with finer $\mathrm{NiO}$ powders presented the best rheological characteristics for PEM purpose. Equally, the optimal loading was increased from 50 to 65 vol.\% using a fine $\mathrm{NiO}(\mathrm{D} 50=0.7 \mu \mathrm{m})$ instead of a coarse $\mathrm{NiO}(\mathrm{D} 50=8 \mu \mathrm{m})$. The effectiveness of a combination of solvent and thermal debinding to produce defect-free tubes of $15 \mathrm{~mm}$ of length and $1 \mathrm{~mm}$ of nominal diameter has been proved. The employ of corn starch as a pore forming agent led to a total porosity around 50 vol.\%, along with a reasonably high level of interconnected pores after sintering and reducing steps. Two rather distinct microstructures were obtained when using the fine and coarse $\mathrm{NiO}$ powder. For the sample containing fine $\mathrm{NiO}$ powder, a better connected Ni network was formed and the final microstructure was denser. Thereby, samples with fine NiO powder were selected for cell fabrication. The power densities obtained for the microtubes, produced by this near-net-shape manufacturing process, are very competitive for the scale up to an industrial level presenting clear economic and environmental advantages over other manufacturing process.

\section{Acknowledgements}

Authors would like to thank financial support received from MICINN and Feder program of the European Community (MAT2013-46452-C4-3R and MAT2012- 30763 projects), and Madrid regional government (MATERYENER3CM S2013/MIT-2753 Program).

\section{References}

1. N. Q. Minh, J Am Ceram Soc, 1993, 76, 563-588.

2. S. C. Singhal, Solid State lonics, 2000, 135, 305-313.

3. N. H. Menzler, F. Tietz, S. Uhlenbruck, H. P. Buchkremer and D. Stoever, J. Mater. Sci., 2010, 45, 3109-3135

4. K. S. Howe, G. J. Thompson and K. Kendall, J. Power Sources, 2011, 196, 1677-1686.

5. V.M. Orera, A. Larrea, M.A. Laguna-Bercero, Frontiers in Energy Research, 2014, 2, 22.

6. Y. Du and N. Sammes, J. Power Sources, 2004, 136, 66-71. 
7. R. Campana, R. I. Merino, A. Larrea, I. Villarreal and V. M. Orera, J. Power Sources, 2009, 192, 120-125.

8. N. Akhtar, S. Decent, D. Loghin and K. Kendall, J. Power Sources, 2009, 193, 39-48.

9.T. Suzuki, T. Yamaguchi, K. Hamamoto, H. Sumi and Y. Fujishiro, Rsc Advances, 2011, 1, 911916.

10. H. Sumi, T. Yamaguchi, K. Hamamoto, T. Suzuki and Y. Fujishiro, J Am Ceram Soc, 2013, 96, 3584-3588.

11. S. M. Jamil, M. H. D. Othman, M. A. Rahman, J. Jaafar, A. Ismail and K. Li, Journal of the European Ceramic Society, 2015, 35, 1-22.

12. R. M. German and A. Bose, Injection molding of metals and ceramics, Metal Powder Industries Federation, 1997.

13. M. Trunec, Journal of the European Ceramic Society, 2004, 24, 645-651.

14. J. Sun, Y. Koh, W. Choi and H. Kim, J Am Ceram Soc, 2006, 89, 1713-1716.

15. T. Jardiel, B. Levenfeld, R. Jimenez and A. Varez, Ceram. Int., 2009, 35, 2329-2335.

16. M. Eugenia Sotomayor, L. Maria Ospina, B. Levenfeld and A. Varez, Mater Charact, 2013, 86, 108-115.

17. J. R. Wilson, W. Kobsiriphat, R. Mendoza, H. Chen, J. M. Hiller, D. J. Miller, K. Thornton, P. W. Voorhees, S. B. Adler and S. A. Barnett, Nature materials, 2006, 5, 541-544.

18. A. Sanson, P. Pinasco and E. Roncari, Journal of the European Ceramic Society, 2008, 28, 1221-1226.

19. Y. Liu, M. Mori, Y. Funahashi, Y. Fujishiro and A. Hirano, Electrochemistry communications, 2007, 9, 1918-1923.

20. T. Suzuki, Y. Funahashi, T. Yamaguchi, Y. Fujishiro and M. Awano, Solid State lonics, 2009, 180, 546-549.

21. D. Dong, J. Gao, X. Liu and G. Meng, J. Power Sources, 2007, 165, 217-223.

22. M. Morales, M. Laguna-Bercero, M. Navarro, F. Espiell and M. Segarra, RSC Advances, 2015, 5, 39350-39357.

23. P. Thomas-Vielma, A. Cervera, B. Levenfeld and A. Varez, Journal of the European Ceramic Society, 2008, 28, 763-771.

24. T. Jardiel, M. Eugenia Sotomayor, B. Levenfeld and A. Varez, International Journal of Applied Ceramic Technology, 2008, 5, 574-581.

25. M. E. Sotomayor, B. Levenfeld and A. Varez, Powder Metallurgy, 2011, 54, 103-107.

26. G. Herranz, B. Levenfeld, A. Varez and J. M. Torralba, Powder Metallurgy, 2005, 48, 134138.

27. M. A. Laguna-Bercero, R. Campana, A. Larrea, J. A. Kilner and V. M. Orera, Fuel Cells, 2011, 11, 116-123. 
28. M. A. Laguna-Bercero, R. Campana, A. Larrea, J. A. Kilner and V. M. Orera, J. Electrochem. Soc., 2010, 157, B852-B855.

29. M. A. Laguna-Bercero, A. Ferriz, A. Larrea, L. Correas and V. M. Orera, Fuel Cells, 2013, 13, 1116-1122.

30. F. M. Barreiros and M. T. Vieira, Ceram. Int., 2006, 32, 297-302.

31. D. Husband, N. Aksel and W. Gleissle, Journal of Rheology, 1993, 37, 215-235.

32. A. Metzner, Journal of Rheology, 1985, 29, 739-775.

33. B. Hausnerová, 2010, Polimery, 55, 3-11.

34. R. Hoffman, Transactions of The Society of Rheology, 1972, 16, 155-173.

35. H. A. Barnes, J. Non Newtonian Fluid Mech., 1995, 56, 221-251.

36. U. Yilmazer and D. M. Kalyon, Journal of Rheology 1989, 33, 1197-1212.

37. M. M. Denn, Annu. Rev. Fluid Mech., 2001, 33, 265-287.

38. T. Kataoka, T. Kitano, M. Sasahara and K. Nishijima, Rheologica Acta, 1978, 17, 149-155.

39. A. V. Shenoy, Rheology of filled polymer systems, Springer Science \& Business Media, 1999.

40. J. J. Reddy, N. Ravi and M. Vijayakumar, Journal of the European Ceramic Society, 2000, 20, 2183-2190

41. H. Liu, F. Xie, L. Yu, L. Chen and L. Li, Progress in Polymer Science, 2009, 34, 1348-1368.

42. H. Monzon, M. A. Laguna-Bercero, A. Larrea, B. I. Arias, A. Varez and B. Levenfeld, Int J Hydrogen Energy, 2014, 39, 5470-5476. 